\title{
Impact of Robotic Fellowship Experience on Perioperative Outcomes of Robotic-Assisted Laparoscopic Partial Nephrectomy
}

\author{
Michael A. Moriarty Kenneth G. Nepple \\ Daniel K. Lee James A. Brown \\ Department of Urology, University of lowa, lowa City, lowa, USA
}

\author{
Chad R. Tracy \\ Michael E. Strigenz
}

\section{Key Words}

Partial nephrectomy • Robotics • Laparoscopic surgeries • Fellowship training $•$ Perioperative period

\begin{abstract}
Background: We analyzed differences in patient selection and perioperative outcomes between robotic-fellowship trained and non-fellowship trained surgeons in their initial experience with robotic-assisted laparoscopic partial nephrectomy. Methods: Data through surgeon case 10 was analyzed. Forty patients were identified from two fellowship trained surgeons $(n=20)$ and two non-fellowship trained surgeons $(n=20)$. Results: Fellowship trained surgeons performed surgery on masses of higher nephrometry score (8.0 vs. $6.0, p=0.007$ ) and more posterior location (60 vs. $25 \%$, $\mathrm{p}=0.03$ ). Retroperitoneal approach was more common (50 vs. $0 \%, p=0.0003)$. Fellowship trained surgeons trended toward shorter warm ischemia time (25.5 vs. $31.0 \mathrm{~min}, \mathrm{p}=$ 0.08). There was no significant difference in perioperative complications (35 vs. $35 \%, p=0.45$ ) or final positive margin rates ( 0 vs. $15 \%, p=0.23$ ). Conclusion: Fellowship experience may allow for treating more challenging and posterior tumors in initial practice and significantly more comfort performing retroperitoneal robotic-assisted laparoscopic partial nephrectomy.

Copyright $\odot 2015$ S. Karger AG, Basel
\end{abstract}

\section{KARGER}

Fax +4161306 1234

E-Mail karger@karger.ch

www.karger.com
(C) 2015 S. Karger AG, Basel

1015-9770/14/0091-0019\$38.00/0

Accessible online at:

www.karger.com/cur

\section{Introduction}

In 2015, a projected 61,560 new cases of renal cancer will be diagnosed in the U.S. making it the 6th most common cancer diagnosis in men and 8th most common in women [1]. There has been an increase in incidence of this disease in recent years, with the advent of axial imaging contributing to an increase in diagnosis of small asymptomatic masses [2, 3]. Currently, the AUA recommends partial nephrectomy for all $\mathrm{T} 1 \mathrm{a}(<4 \mathrm{~cm})$ and amenable T1b $(4-7 \mathrm{~cm})$ renal masses via open, laparoscopic partial nephrectomy (LPN), or robotic-assisted laparoscopic partial nephrectomy (RAPN) procedures [4].

The minimally invasive forms of this procedure have been shown to provide similar oncologic outcomes to open nephrectomy while shortening hospital length of stay and minimizing intraoperative blood loss when performed by experienced surgeons [5]. LPN, however, is considered a challenging procedure with a significant complication rate and learning curve [6]. It has been suggested that RAPN presents a more accessible platform to perform this complex urologic procedure in a minimally invasive manner [6-8] while equating or improving upon estimated blood loss, warm ischemia time (WIT), and hospital length of stay (LOS) seen with LPN [7-9]. A number of retrospective reviews and case series have attempted to define this learning curve with several showing a plateau in surgeon skill surrogate measures

James A. Brown

Department of Urology, University of Iowa

200 Hawkins Dr., 3 RCP

IA 52242-1089, Iowa City (USA)

E-Mail james-brown-2@uiowa.edu 
between 20 and 30 cases [7, 10]. Importantly, it has been previously reported that positive surgical margin in the setting of RAPN correlates to disease progression [11]. However, these studies have presented little discussion of surgeon factors which may have influenced these outcomes as well as operative decision making.

Currently, there is little consensus regarding the necessary training required for surgeons to become proficient in robotic surgery techniques. The Endourological Society currently requires endourology fellows to undertake 60 laparoscopic cases over the course of 2 years of training with no specific robotic surgery requirements [12]. We undertook a retrospective chart review, evaluating robotically-assisted partial nephrectomies. These were performed at a single academic center between 2009 and 2013 by 4 urologic surgeons. Of these individuals, 2 had procedure-specific experience in fellowship. Comparisons were made based on whether surgeons had experience with RAPN in fellowship.

\section{Materials and Methods}

\section{Study Population}

Upon Institutional Review Board approval, we obtained and reviewed the records for all patients who have undergone RAPN at our institution. The inclusion criterion was defined as all patients who underwent RAPN within a given surgeon's first 10 cases following completion of fellowship training. Patient data was excluded from the analysis if surgeon had less than 10 RAPN cases. This was done to eliminate the potential for final data skewed to represent less experienced surgeons. Data from a total of 40 patients and 4 surgeons was reviewed.

\section{Study Design}

This study was formulated as a retrospective outcomes review of the patient cohorts undergoing RAPN by surgeons with and without procedure specific fellowship experience. Patient demographic, imaging, operative, and pathologic data were collected. Preoperative contrast CT or MRI imaging was collected from all patients. Renal masses graded according to the R.E.N.A.L. nephrometry score grading system to stratify renal mass complexity by location, depth, and size [13].

Intraoperative and postoperative complications up to 60 days were collected. Perioperative complication data was graded according the Clavien-Dindo grading system $[14,15]$. Tumor violation intraoperatively was defined as entry into the mass. A positive surgical margin was considered present if the deepest resected margin had abutting tumor on final pathology report. Positive margins at the first resected margin in cases requiring a second deep margin were recorded separately.

\section{Data Analysis}

Following our chart review, the raw data was analyzed according to the attending surgeon identified in the operative note. Clinical, operative and pathologic data was then separated and
Table 1. Patient and renal mass characteristics: differences between fellowship-trained and non-fellowship-trained surgeons

\begin{tabular}{llll}
\hline & $\begin{array}{c}\text { Fellowship } \\
\text { trained }\end{array}$ & $\begin{array}{c}\text { Non-fellowship } \\
\text { trained }\end{array}$ & $\mathrm{p}$ \\
\hline Patients & 20 & 20 & \\
Age (median) & 54.3 & 55.6 & 0.32 \\
Male & $10(50 \%)$ & $10(50 \%)$ & 1.00 \\
BMI (median) & 30.6 & 29.2 & 0.21 \\
Past abdominal procedure & $12(60 \%)$ & $14(70 \%)$ & 0.51 \\
Solitary kidney & 0 & $1(5 \%)$ & 1.00 \\
Renal nephrometry score & & & \\
$\quad$ High Complexity (10-12) & 0 & 0 & 0.0009 \\
$\quad$ Moderate Complexity (7-9) & 18 & 8 & \\
$\quad 20 w$ Complexity (4-6) & 2 & 12 & 0.007 \\
Median Nephrometry Score & 8.0 & 6.0 & 0.002 \\
Radiologic diameter (median) & 2.6 & 1.9 & 0.03 \\
Posterior tumors & $12(60 \%)$ & $5(25 \%)$ & 0.34 \\
Laterality (right-sided) & $13(65 \%)$ & $10(50 \%)$ & \\
\hline
\end{tabular}

Table 2. Operative data

\begin{tabular}{llll}
\hline & $\begin{array}{c}\text { Fellowship } \\
\text { trained }\end{array}$ & $\begin{array}{c}\text { Non-fellowship } \\
\text { trained }\end{array}$ & $\mathrm{p}$ \\
\hline $\begin{array}{l}\text { Concurrent procedure } \\
\text { Retroperitoneal approach }\end{array}$ & 0 & $3(15 \%)$ & 0.23 \\
$\begin{array}{l}\text { Conversions } \\
\text { Medianoperative period (min.) }\end{array}$ & $\begin{array}{l}10(50 \%) \\
\text { Clamp statistics }\end{array}$ & $0(0 \%)$ & 0.0003 \\
$\quad$ Clamped & $17(85 \%)$ & $0(0 \%)$ & 0.31 \\
$\quad$ Median Warm Ischemia & 25.5 & 240.0 & 0.79 \\
$\begin{array}{l}\text { Time (WIT, min.) } \\
\quad \text { WIT, unclamped excluded }\end{array}$ & 27.0 & 31.0 & \\
$\begin{array}{l}\text { Tumor violation } \\
\text { Second margin taken }\end{array}$ & $3(16 \%)$ & 42.0 & 0.96 \\
Medianestimated blood loss (cc) & $5(26 \%)$ & $4(20 \%)$ & 0.08 \\
$\quad 100.0$ & 150.0 & 0.94 \\
\hline
\end{tabular}

compared in cohorts of cases performed by fellowship-trained (FT) surgeons and those non-fellowship trained (NFT) surgeons. Statistical significance $(\mathrm{p}<0.05)$ was determined utilizing the Chi-Squared test and the Mann-Whitney U test given the likely non-parametric nature of our data set.

\section{Objectives}

We hypothesized that the above data would show clinical benefit to patients undergoing RAPN in the initial experience of surgeons who had procedure specific fellowship experience. Specifically, we would expect to see lower operative times, complication rates, and hospital length of stay. Secondary objectives of this study were to define surgeon selection criteria in their initial experience with the procedure as defined by prior training experience. This was to be evaluated by identifying differences in the respective groups by complexity of masses excised, operative approach selection, and selected patient demographics. 
Table 3. Postoperative data

\begin{tabular}{llll}
\hline & $\begin{array}{c}\text { Fellowship } \\
\text { trained }\end{array}$ & $\begin{array}{c}\text { Non-fellowship } \\
\text { trained }\end{array}$ & $\mathrm{p}$ \\
\hline $\begin{array}{l}\text { Medianpostoperative LOS (d) } \\
\text { Clavien complications }\end{array}$ & 2.0 & 3.0 & 0.34 \\
$\quad$ & 7 & & \\
2 & 2 & 4 & \\
3 & 1 & 4 & \\
4 & 0 & 3 & \\
5 & 0 & 0 & \\
$\quad$ Total & 10 & 12 & 0.81 \\
Patients with complications & $7(35 \%)$ & $7(35 \%)$ & 1.00 \\
Patients with III+IV complications & $1(5 \%)$ & $4(20 \%)$ & 0.34 \\
Readmissions & $0(0 \%)$ & $4(20 \%)$ & 0.11 \\
\hline
\end{tabular}

Table 4. Pathologic outcomes

\begin{tabular}{|c|c|c|c|}
\hline & $\begin{array}{c}\text { Fellowship } \\
\text { trained }\end{array}$ & $\begin{array}{c}\text { Non-fellowship } \\
\text { trained }\end{array}$ & $\mathrm{p}$ \\
\hline Pathologic diagnosis & & & 0.74 \\
\hline $\mathrm{RCC}$ & 20 & 17 & \\
\hline Oncocytoma & 0 & 2 & \\
\hline Angiomyolipoma & 0 & 1 & \\
\hline Positive initial extirpated margin & $3(15 \%)$ & $3(15 \%)$ & 1.00 \\
\hline Tumor present in re-resected margin & & & 0.78 \\
\hline $\mathrm{Y}$ & $0(0 \%)$ & $1(33 \%)$ & \\
\hline $\mathrm{N}$ & 5 & 2 & \\
\hline Positive final margin & $0(0 \%)$ & $3(15 \%)$ & 0.23 \\
\hline
\end{tabular}

\section{Results}

This analysis included a total of 40 RAPNs performed at our institution between December 2009 and June 2014. Of these cases, 20 were performed by the FT cohort. Three RAPNs were excluded from operative time analysis as they underwent additional procedures which confounded the recorded procedure duration. All of these individuals were in the NFT cohort. Conversion to open nephrectomy was required in one case.

There were no statistically significant differences between the 2 patient groups in age, gender, BMI, and number of prior abdominal procedures. There was a statistically significant difference in tumor location, size, and complexity (table 1). Tumors operated on by FT surgeons were more often posterior ( $0.60 \mathrm{vs} .0 .25, \mathrm{p}=0.03$ ), larger ( 2.6 vs. $1.9 \mathrm{~cm}, \mathrm{p}=0.002$ ), and more complex as defined by the R.E.N.A.L. nephrometry scoring system. (8.0 vs. $6.0, p=0.007)$.
The 2 groups were equivalent in terms of procedure duration; however, some differences did exist (table 2). The FT cohort more often undertook a retroperitoneal approach to excision of renal masses with the NFT cohort never attempting this method $(50$ vs. $0 \%, \mathrm{p}=$ 0.0003). The FT group performed 3 off-clamp mass excisions; one was performed by the NFT cohort (15 vs. $5 \%, \mathrm{p}=0.96)$. There was a trend toward lower WIT in FT surgeons when accounting for off-clamp excisions (25.5 vs. $31.0 \mathrm{~min}, \mathrm{p}=0.08)$ and when excluding off-clamp cases ( 27.0 vs. $32.0 \mathrm{~min}, \mathrm{p}=0.10$ ), but that trend was not statistically significant. FT and NFT surgeons entered the renal mass of interest on excision 3 and 4 times, respectively; there was no statistical difference between these two groups $(p=0.94)$. There were no intraoperative complications in either cohort.

Postoperatively, patients had complications at an equivalent rate ( 35 vs. $35 \%, \mathrm{p}=1.00)$ with no differences in severity ( 5 vs. $20 \%, p=0.34$; table 3 ). Notable complications in the NFT cohort included one urinoma and two episodes of bleeding requiring embolization by the interventional radiology service. Notable FT cohort complications included an incisional hernia at a port site and a pneumothorax which resolved with conservative management.

Both FT and NFT surgeons excised 3 masses with positive margins on their initial extirpation (table 4). In five and two instances, respectively, FT and NFT surgeons undertook a second resection due to concern for a positive margin. Following such excisions FT surgeons successfully achieved a negative final margin at a higher rate compared to NFT surgeons; however, this difference lacked significance (100 vs. $15 \%, \mathrm{p}=0.23$ ).

\section{Discussion}

This study presents the operative and pathologic outcomes from a series of RAPNs at our institution between December 2009 and June 2014. These cases were distributed between four surgeons - two with RAPN experience in fellowship training and two without such experience. In the past at our institution, challenging minimally invasive procedures such as partial nephrectomies were undertaken by select high volume surgeons with extensive training in laparoscopy. With the majority of minimally invasive procedures being undertaken via robot, previously challenging laparoscopic procedures have become more accessible to surgeons without extensive laparoscopic training beyond residency. While the efficacy,

Curr Urol 2015;9:19-23 
safety, and cost of RAPN has been described at length previously [7, 9-11, 16-21], there is a paucity of data describing differences in initial outcomes in those with and without procedure-specific training. The potential for worse initial outcomes or, more interestingly, equivalent outcomes, poses the question regarding the need for further training. Currently, there is little consensus regarding the training needs of individuals undertaking robotic procedures.

Leroy et al. [22] addressed similar questions in the setting of robot-assisted laparoscopic prostatectomy by comparing initial outcomes between experienced open surgeons and fellowship-trained robotic surgeons (FT). This study found lower positive surgical margin rates (0.15 vs. $0.34, p=0.008)$ and open conversion rates in the FT cohort in the first 30 cases of this procedure. Furthermore, the FEL cohort was more likely to complete pelvic lymph node dissection $(\mathrm{p}=0.043)$ despite patients having lower clinical stage disease $(\mathrm{p}=0.003)$, less likely to have prolonged urethral catheter drainage ( $>14 \mathrm{~d}$ ), and less likely to require reoperation. Outcomes were similar to the FT cohort in the open group's subsequent 30 cases. Although similar differences in outcomes may exist in the setting of RAPN, lower volume has not allowed our study to identify a statistically significant difference in the same parameters. There was, however, little evidence to suggest differences in complication rates, reoperation rate, and operative period in the setting of RAPN.

Perhaps unique to renal tumors, and of interest in this study, is the presence of a considerable amount of anatomic tumor variation compared to other malignancies and the potential to influence operative approach. In the setting of partial nephrectomy this has resulted in many surgeons choosing between a transperitoneal and retroperitoneal approach for anterior and posterior tumors, respectively. Previous work in the setting of LPN revealed reduced operative periods, shorter WIT, and shorter hospital stays for tumors which were excised via a retroperitoneal approach [23]. Although the data remains limited on retroperitoneal RAPN, in previous series $12-39 \%$ of these procedures were performed with a retroperitoneal approach $[24,25]$. The sample sizes of these studies $(\leq$ 10 RAPN) were not powered to evaluate the variables of WIT, operative time, and length of stay. Our FT surgeons more often excised posterior tumors robotically and utilized a retroperitoneal approach to tumor excision suggesting increased comfort with these locations and approach, respectively. Furthermore, in the subsequent 40 NFT cases following their initial 10 (data not presented), our NFT did not perform a retroperitoneal approach. Of note, in addition to the differences in operative approach, tumors excised by FT surgeons were more complex and larger when compared to those excised by their NFT counterparts. The significant difference in patient selection which occurred between our groups suggests a period in which individuals without prior training undertake cases which will allow for acceptable operative outcomes and complication rates early in their experience. This selection could have contributed in part to the observed equivalence in WIT, complications, and margin status which may have been otherwise unexpected in a cohort of surgeons without procedure-specific experience.

The presented study has several limitations. It was a retrospective chart review in design and included a relatively small sample size in both of our compared groups. Thus, few definitive statements can be made regarding outcomes between these two groups as the data sets are underpowered and were not accrued for the purpose of this study. Further work from our hypothesis generating study would benefit from prospective studies with a larger cohort of NFT and FT surgeons for comparison of initial outcomes. Furthermore, a larger case volume per surgeon would be of added benefit to evaluate time needed to attain equivocal outcomes and operative decision-making in NFT surgeons if such differences truly exist. If there were indeed a difference between these groups which was of significant clinical outcomes, it would be of interest to identify means to close deficits and improve patient outcomes. Conversely, if no benefit were to exist in the setting of the more accessible robotic approach to these procedures, could there be significant cost-saving to surgeons through reductions in what is felt to be necessary length of training? Currently there is little consensus regarding the training needs of surgeons in the setting of robotic-assisted laparoscopic intervention, including RAPN, to prepare them for safe, effective clinical practice

\section{Conclusion}

RAPN has become a method of choice for performing nephron-sparing surgery and provides a platform accessible to urologic surgeons of varying training background. Although considerable work has been performed to describe the learning curve and operative outcomes of this procedure, less work has been conducted on description of its modifiers and the modifiers of operative 
decision making. Our experience has shown that RAPN fellowship experience may allow for treating more challenging and posterior tumors in initial practice and a significant increase in likelihood of performing RAPN via retroperitoneal approach. Further evaluation of the benefits of fellowship RAPN will better define training needs for surgeons to allow for improved clinical outcomes for the patients they serve.

\section{References}

1 Siegel RL, Miller KD, Jemal A: Cancer statistics, 2015. CA Cancer J Clin 2015;65:5-29.

2 Kane CJ, Mallin K, Ritchey J, Cooperberg MR, Carroll PR: Renal cell cancer stage migration: analysis of the National Cancer Data Base. Cancer 2008;113:78-83.

3 Nepple KG, Yang L, Grubb RL 3rd, Strope SA: Population based analysis of the increasing incidence of kidney cancer in the United States: evaluation of age specific trends from 1975 to 2006. J Urol 2012;187:32-38.

4 Novick AC, Campbell SC, Belldegrun A, Blute ML, Chow GK, Derweesh IH, Faraday MM, Kaouk JH, Leveillee RJ, Matin SF, Russo P, Uzzo RG: Guideline for management of the clinical T1 renal mass. J Urol 2009; 182:1271-1279.

5 Gill IS, Kavoussi LR, Lane BR, Lane BR, Blute ML, Babineau D, Colombo JR Jr, Frank I, Permpongkosol S, Weight CJ, Kaouk JH, Kattan MW, Novick AC: Comparison of 1,800 laparoscopic and open partial nephrectomies for single renal tumors. J Urol 2007; 178:41-46.

6 Gill IS, Matin SF, Desai MM, Kaouk JH, Steinberg A, Mascha E, Thornton J, Sherief MH, Strzempkowski B, Novick AC: Comparative analysis of laparoscopic versus open partial nephrectomy for renal tumors in 200 patients. J Urol 2003;170:64-68.

7 Ellison JS, Montgomery JS, Wolf JS Jr, Hafez KS, Miller DC, Weizer AZ: A matched comparison of perioperative outcomes of a single laparoscopic surgeon versus a multisurgeon robot-assisted cohort for partial nephrectomy. J Urol 2012;188:45-50.

8 Deane LA, Lee HJ, Box GN, Melamud O, Yee DS, Abraham JB, Finley DS, Borin JF, McDougall EM, Clayman RV, Ornstein DK: Robotic versus standard laparoscopic partial/ wedge nephrectomy: a comparison of intraoperative and perioperative results from a single institution. J Endourol 2008;22:947-952.
9 Benway BM, Bhayani SB, Rogers CG, Dulabon LM, Patel MN, Lipkin M, Wang AJ, Stifelman MD: Robot assisted partial nephrectomy versus laparoscopic partial nephrectomy for renal tumors: a multi-institutional analysis of perioperative outcomes. J Urol 2009;182:866-873.

10 Mottrie A, De Naeyer G, Schatteman P, Carpentier P, Sangalli M, Ficarra V: Impact of the learning curve on perioperative outcomes in patients who underwent robotic partial nephrectomy for parenchymal renal tumors. Eur Urol 2010;58:127-133.

11 Khalifeh A, Kaouk JH, Bhayani S, Rogers C, Stifelman M, Tanagho YS, Kumar R, Gorin MA, Sivarajan G, Samarasekera D, Allaf ME: Positive surgical margins in robot-assisted partial nephrectompy: a multi-institutional analysis of oncological outcomes (leave no tumor behind). J Urol 2013;190:1674-1679.

12 Endourological Society. Requirements for Endourology Fellowship. Available from: http://www.endourological.org/fellowship/ index.html. Accessed August 16, 2014.

13 Kutikov A, Uzzo RG: The R.E.N.A.L. nephrometry score: a comprehensive standardized system for quantitating renal tumor size, location and depth. J Urol 2009;182:844-853.

14 Clavien PA, Sanabria JR, Strasberg SM: Proposed classification of complications of surgery with examples of utility in cholecystectomy. Surgery 1992;111:518-526.

15 Dindo D, Demartines N, Clavien PA: Classification of surgical complications: a new proposal with evaluation in a cohort of 6336 patients and results of a survey. Ann Surg 2004;240:205-213

16 Aron M, Koenig P, Kaouk JH, Nguyen MM, Desai MM, Gill IS: Robotic and laparoscopic partial nephrectomy: a matched-pair comparison from a high-volume centre. BJU Int 2008;102:86-92.

17 Benway BM, Bhayani SB, Rogers CG, Porter JR, Buffi NM, Figenshau RS, Mottrie A: Robot-assisted partial nephrectomy: an international experience. Eur Urol 2010;57:815820 .
18 Mir SA, Cadeddu JA, Sleeper JP, Lotan Y: Cost comparison of robotic, laparoscopic, and open partial nephrectomy. J Endourol 2011;25:447-453.

19 Rogers CG, Menon M, Weise ES, Gettman MT, Frank I, Shephard DL, Abrahams HM : Robotic partial nephrectomy: a multi-institutional analysis. J Robotic Surg 2008;2:141143.

20 Spana G, Haber GP, Dulabon LM, Petros F, Rogers CG, Bhayani SB, Stifelman MD, Kaouk JH: Complications after robotic partial nephrectomy at centers of excellence: multi-institutional analysis of 450 cases. J Urol 2011;186:417-422.

21 Tanagho YS, Kaouk JH, Allaf ME, Rogers CG, Stifelman MD, Kaczmarek BF, Hillyer SP, Mullins JK, Chiu Y, Bhayani SB: Perioperative complications of robot-assisted partial nephrectomy: analysis of 886 patients at 5 United States centers. Urology 2013;81:573579.

22 Leroy TJ, Thiel DD, Duchene DA, Parker AS, Igel TC, Wehle MJ, Goetzl M, Thrasher JB: Safety and peri-operative outcomes during learning curve of robot-assisted laparoscopic prostatectomy: a multi-institutional study of fellowship-trained robotic surgeons versus experienced open radical prostatectomy surgeons incorporating robot-assisted laparoscopic prostatectomy. J Endourol 2010;24: 1665-1669.

23 Ng CS, Gill IS, Ramani AP, Steinberg AP, Spaliviero M, Abreu SC, Kaouk JH, Desai MM: Transperitoneal versus retroperitoneal laparoscopic partial nephrectomy: patient selection and perioperative outcomes. J Urol 2005; 174:846-489.

24 Tanaka K, Shigemura K, Furukawa J, Ishimura T, Muramaki M, Miyake H, Fujisawa: Comparison of the transperitoneal and retroperitoneal approach in robot assisted partial nephrectomy in an initial case series in Japan. J Endourol 2013;27:1384-1388.

25 Feliciano J, Stifelman M: Robotic retroperitoneal partial nephrectomy: a four-arm approach. JSLS 2012;16:208-211. 